\title{
In silico studies of isatinyl-2- aminobenzoylhydrazone transition metal complexes against cyclin-dependent kinase 6 (CDK6)
}

\author{
Yesaya Reformyada Nusantoro, Arif Fadlan* \\ Department of Chemistry, Institut Teknologi Sepuluh Nopember, Surabaya, Indonesia \\ *Corresponding author: ITS Sukolilo Campus, Surabaya, 60111 East Java, Indonesia. Email: afadlan@chem.its.ac.id
}

\begin{abstract}
Cyclin-dependent kinase 6 (CDK6) is an important member of protein kinases, involving in many cellular pathways especialy cell cycle progression. Thus, CDK6 is a promising target in cancer therapy. This report aims to predict inhibiton of CDK6 by some complex compounds by using molecular docking and pharmacological properties analysis. Those compounds are isatinyl-2-aminobenzoylhydrazone (ISABH) and cobalt (II), nickel (II), copper (II), and zinc (II) transition metal complexes. The molecular docking against CDK6 (PDB code: 3NUP) revealed that ISABH/ISABH-transition metal complexes established ligand-protein interaction as expressed by negative binding affinity values. Drug-likeness by SwissADME indicated that ISABH and Ni-ISABH met the Lipinski's rule of five. Both compounds also showed reasonable pharmacological criteria by admetSAR.
\end{abstract}

Keywords: Cyclin-dependent kinase, CDK6 inhibitors, drug-likeness, ADMET, isatinyl-2-aminobenzoylhydrazone

\section{Introduction}

Kinases are proteins that involved in the cellular pathways such as signal transduction and cell cycle progression mainly through phosphorylation [1]. Cyclin-dependent kinases (CDKs) are a member of the CMGC family of serine/threonine kinases and interact with cyclins to activate their catalytic action in cell cycle $[2,3]$. CDKs control the order of cell cycle development with specific cyclins and CKIs [4]. CDK6 gene is located on chromosome 7 in humans extends 231,706 base pairs and involves in cell cycle progression by encoding a 326 amino acids protein [5]. The activity of this kinase is controlled by the D-type cyclins regulatory subunits and CDK inhibitors i.e INK4 family. CDK6, as well as CDK4, has been shown to phosphorylate, and thus regulate the activity of retinoblastoma protein $(\mathrm{Rb})$, a tumor suppressor protein [6]. The pathway of cyclin D-CDK4/6-INK4$\mathrm{RB}$ has been observed in several cancer types due to uncontrolled cell cycle/growth [7]. Thus, these kinases are being used as a potential target of cancer therapeutic research and development. Palbociclib, a nitrogen-containing heterocyclic compound of CDK4/ CDK6 targeted therapy, is approved for the treatment of breast cancer [8].
Isatin (1H-indole-2,3-dione) is a diketo ( $\mathrm{C} 2$ and C3) heterocyclic compound derived from indole with transition metal ions binding capacity [9]. Isatin is also known for its flexible structure and diverse biological activities i.e. antiinflammation, antibacterial, anti-HIV, and anticancer CDK inhibitors [10]. Several isatin derivatives affected the proliferation of human breast cancer MCF-7 and/or MDA-MB-231 cell lines and displayed as efficient and potent inhibitors for CDK2, CDK4, CDK9 [11,12]. Hydrazones with the azometin group, $-\mathrm{CH}=\mathrm{N}-\mathrm{NH}-$, are also exhibited various bioactivities including antimicrobial, anticonvulsant, analgesic, antiinflammatory, antiplatelet, antituberculosis, and antitumor. The carbon-nitrogen double bond plays an important role in the design and development of drugs [13]. Various transition metals of isatin-hydrazone complexes have been developed and further investigated in order to study their anticancer properties [14]. The present study reports on an attempt to develop CDK6 inhibitors based on the chemistry of isatin-hydrazone.

\section{Methods}

\section{Protein preparation}

The CDK6 (PDB ID: 3NUP) crystal structure with a resolution of $2.60 \AA$ was retrieved from protein data 
bank (https://www.rscb.org)[15]. The protein target preparation and optimization were executed with PyMOL by removing water molecules and $3 \mathrm{NU}$ cocrystalline ligand followed by the addition of hydrogen atoms. The 3D protein structure was then stored in $\mathrm{pdb}$ format and converted into dockable pdbqt format for docking.

\section{Ligand preparation}

The two-dimensional (2D) structure of isatinyl-2aminobenzoylhydrazone (ISABH) and its transition metals Co (II), Ni (II), Cu (II), and Zn (II) complexes (Figure 1) were constructed using MarvinSketch and converted into a three-dimensional (3D) structure followed by protonation at a $\mathrm{pH}$ of 7.4 [16]. The geometry optimization was carried out using MMFF94 and the optimized structures were further saved into pdbqt format getting ready for docking process.

\section{Molecular docking}

Docking was performed at MacBook Pro 2018 running on Intel $^{-}$Core i5 quad-core $2.3 \mathrm{GHz}, 8 \mathrm{~GB}$ RAM with Intel Iris Plus Graphics 655 graphics card and MacOS Mojave 10.14.5 operating system. Flexible docking was accomplished using AutoDock Vina [17] in PyRx [18] with a grid size of X $16 \AA$, Y $16 \AA$, $\mathrm{Z} 16 \AA$ and $\mathrm{X}, \mathrm{Y}, \mathrm{Z}$ dimensions of $38,9 \AA, 27,3 \AA$, $-12,3 \AA$ resulted from the $3 \mathrm{NU}$ co-crystal binding location. Docking parameters and scoring function were set as default. The metal ions of the ISABH's complexes were automatically recognized by Autodock Vina as prepared in pdbqt format for ligands. Docking procedure was evaluated by redocking method based on RMSD $<2 \AA$ and interactions [19]. The binding modes and receptor-ligand interaction were analyzed by using $P y M O L$.

\section{Drug likeness and ADMET prediction}

Drug-likeness analysis was assessed according to Lipinski's rule of five using SwissADME online web tool [20]. The pharmacological properties prediction based on absorption, distribution, metabolism, excretion, and toxicity (ADMET) was generated by using admetSAR [21].

\section{Results}

\section{Molecular docking}

$3 \mathrm{NU}$ co-crystal was successfully re-docked back to the binding site of the 3NU-3NUP complex in order to validate the docking process. The alignment of the docked $3 \mathrm{NU}$ best pose to the $3 \mathrm{NU}$ co-crystallized showed a root-mean-squared deviation (RMSD) value of $1.083 \AA$ (Figure 2a). The docked 3NU also indicated the same interactions compared to $3 \mathrm{NU}$ co-crystal in 3NUP complex (Figure 2b).

The cross-docking of ISABH and its complexes with metal ions of cobalt (II), nickel (II), copper (II), and zinc (II) on CDK6 protein (PDB ID: 3NUP) produced binding affinity of $-9.4 ;-8.5 ;-6.6 ;-6.5 ;-5.4 \mathrm{kcal} / \mathrm{mol}$ for $\mathrm{Ni}-\mathrm{ISABH}, \mathrm{ISABH}, \mathrm{Co}-\mathrm{ISABH}, \mathrm{Cu}-\mathrm{ISABH}$, and $\mathrm{Zn}-$ ISABH, respectively. Visualization of docking results using PyMOL was then carried out to determine the interactions and bind modes of ligands with 3NUP protein. Ni-ISABH interacted with Glu 99 and Asp 104 residues through hydrogen bonding (Figure 3). CoISABH, Cu-ISABH, and Zn-ISABH showed the same interaction with Asp 104 residue by hydrogen bonding. The interaction with Val 101 residue was demonstrated by ISABH as found in the $3 \mathrm{NU}$ co-crystals (Figure 4).

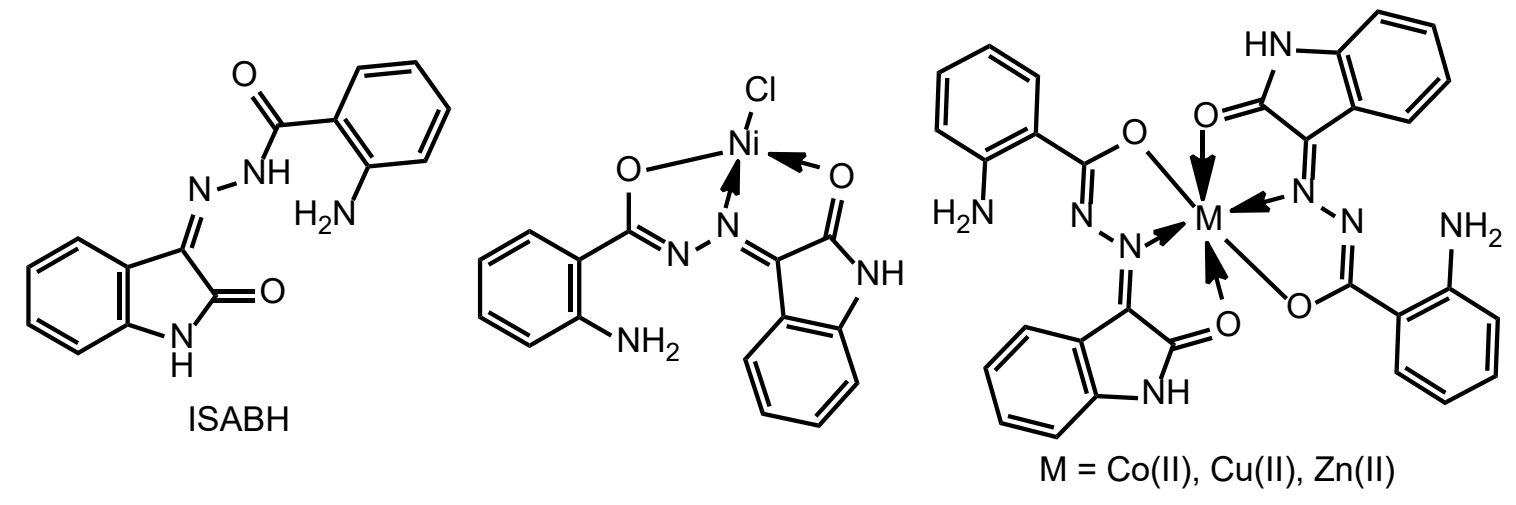

Figure 1. 2D structure of ISABH and Co (II), Ni (II), Cu (II), and Zn (II) transition metals complexes 


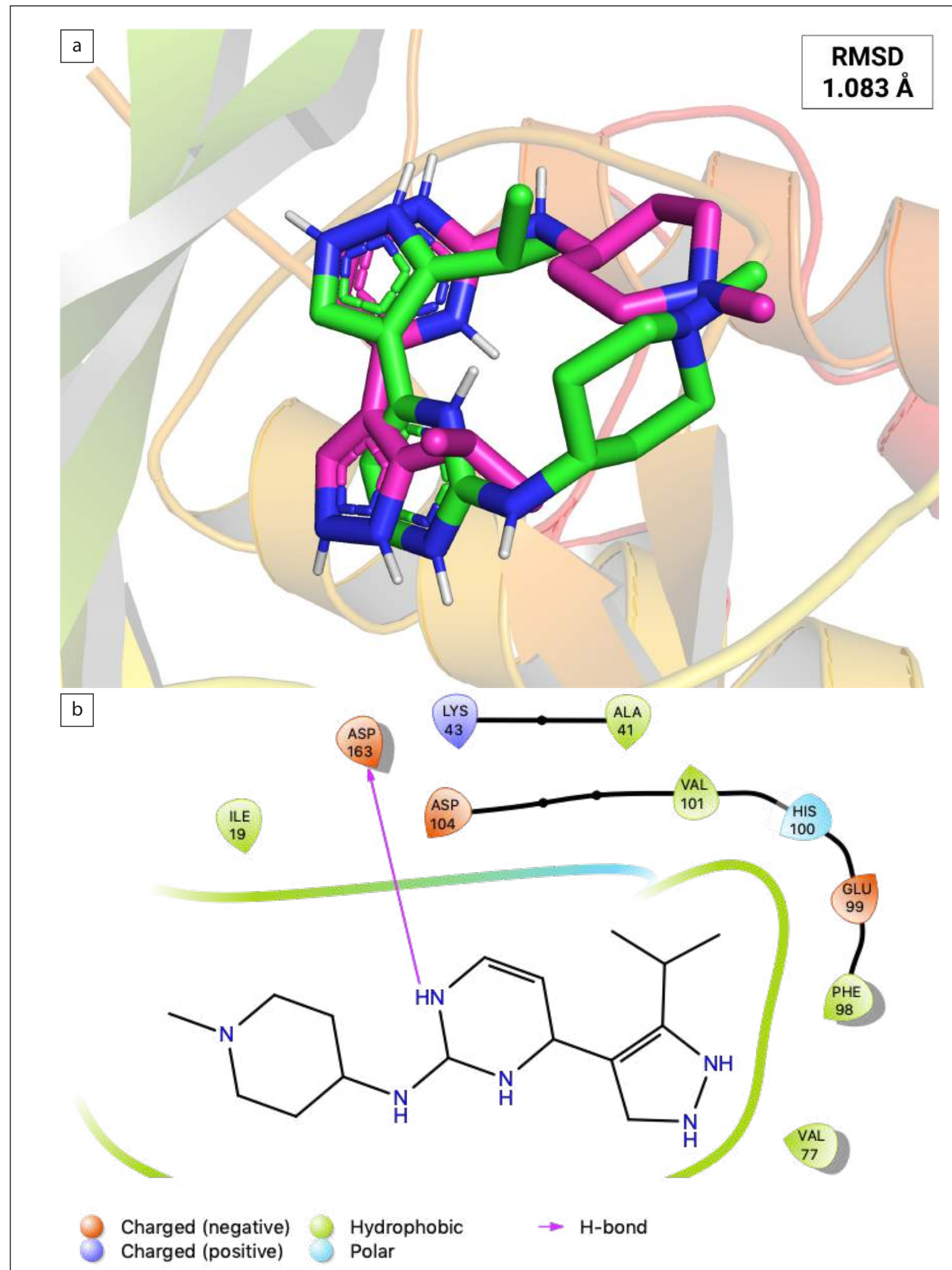

Figure 2. Docking visualization. (a) $3 \mathrm{D}$ representation of $3 \mathrm{NU}$ native ligand (green) and $3 \mathrm{NU}$ redocked (magenta) alignment, and (b) 2D representation of interaction between CDK6 and 3NU redocked 


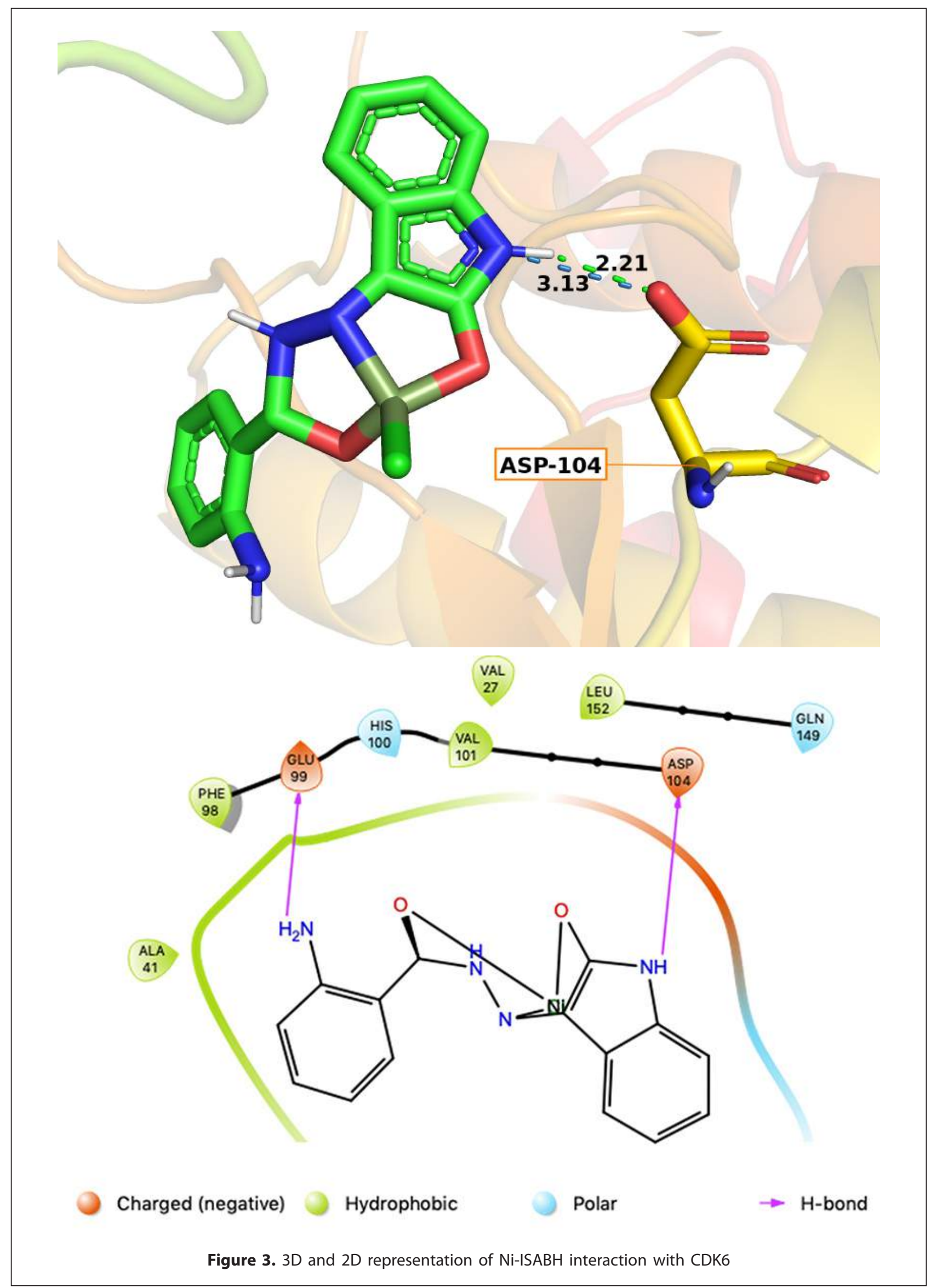




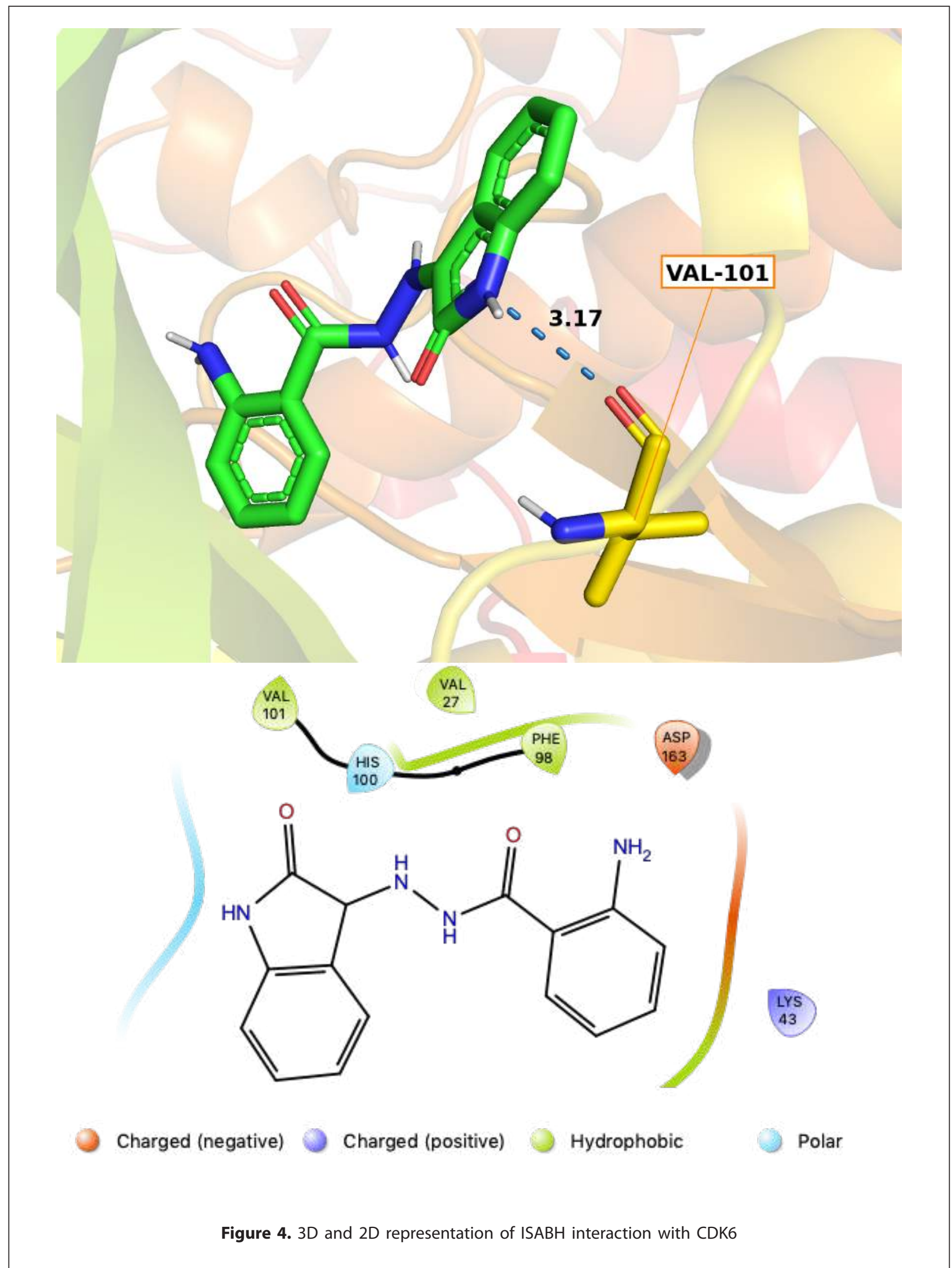




\section{ADMET profile}

Table 1 summarizes the results of drug-likeness analysis using SwissADME. ISABH and its complexes with cobalt (II), nickel (II), copper (II), and zinc (II) showed $\log \mathrm{P}$ of 1.44-2.48, hydrogen bond acceptors 6-12, hydrogen bond donors $4-6$, and molecular weights 280.28-623.93. The pharmacological properties prediction of ISABH and Ni-ISABH using admetSAR are shown in Table 2. ISABH and Ni-ISABH exhibited positive values for human intense absorption, human oral bioavailability, and blood brain barrier. Both were also non-inhibitory non-substrate for P-glycoprotein inhibition and substrate parameters and were noncarcinogenic. The acute oral toxicities of ISABH and Ni-ISABH were 2,057 and 2,810, while the plasma protein binding values were 0.677 and 0.807 .

\section{Discussion}

The binding modes of protein-ligand CDK6 3NU co-crystal was reproduced by redocking method prior to docking study. This method was carried out by removing 3NU co-crystal from the binding site of 3NUP and inserting back to the same position [22]. The redocking procedure was successfully done and alignment of the re-docked $3 \mathrm{NU}$ to $3 \mathrm{NU}$ co-crystal gave RMSD value of $1.083 \AA$. Further, the docked 3NU ligand interacted with Val 101 through hydrogen bonding as in co-crystallized 3NU. These two parameters are enough in reproducing the interaction of $3 \mathrm{NU}$ and 3NUP crystal structure and indicate that it can be extended for the next assessment [23].
The transition metal of Co (II), Ni (II), Cu (II) and $\mathrm{Zn}$ (II) complexes are well known for their interaction in the biological system as metalloprotein together with iron. Transition metal complexes also present as active substances in several inorganic-based pharmaceuticals for bioinorganic applications against various diseases, ranging from antibacterial to anticancer. In addition, these first-row transition metals are also have less toxic properties, affordable, and easily available [24]. The transition metals Co (II), Ni (II), Cu (II) and Zn (II) coordinates ISABH in a $3 \mathrm{D}$ conformation and enables them to optimally match on 3NUP. This ability mainly relies on the electron affinity which relates to metalligand polarization [25]. Cross-docking of ISABH, CoISABH, Cu-ISABH, Ni-ISABH, and Zn-ISABH was perfomed against CDK-6 protein (PDB ID: 3NUP). The binding affinity determined the strength of ligands and protein interaction indicates the more negative value the better binding strength and suggests the better molecular docking prediction [18]. Ni-ISABH displayed the lowest binding affinity among others with a value of $-9.4 \mathrm{kcal} / \mathrm{mol}$. The binding affinity of Co-ISABH, Cu-ISABH, Zn-ISABH was 6.6, 6.5, and $5.4 \mathrm{kcal} / \mathrm{mol}$, respectively, and the order of binding affinity was Ni-ISABH $>$ ISABH $>$ Co-ISABH $>\mathrm{Cu}-$ ISABH $>$ Zn-ISABH. The different binding affinity for each complexes relates to their structure (Figure $1)$, shielding effect of metal complexes, and metalcoordinating atom distances. As shown in Figure 1, metal ions of $\mathrm{Co}$ (II), $\mathrm{Cu}$ (II) and $\mathrm{Zn}$ (II) formed $\mathrm{ML}_{2}$ type coordination with ISABH in octahedral fashion and is classified as sufficiently coordinated metal ion

Table 1. In silico drug likeness prediction using SwissADME

\begin{tabular}{cccccc}
\hline Compounds & Molecular weight & $\log$ P & $\begin{array}{c}\text { H-bond } \\
\text { acceptor }\end{array}$ & $\begin{array}{c}\text { H-bond } \\
\text { donor }\end{array}$ & $\begin{array}{c}\text { Lipinski's } \\
\text { violation }\end{array}$ \\
\hline ISABH & 280.28 & 1.57 & 6 & 4 & 0 \\
Cu- ISABH & 622.09 & 2.47 & 12 & 6 & 1 \\
Co- ISABH & 617.48 & 2.47 & 12 & 6 & 1 \\
Ni- ISABH & 375.44 & 1.44 & 6 & 4 & 0 \\
Zn- ISABH & 623.93 & 2.48 & 12 & 6 & 1 \\
\hline
\end{tabular}

Table 2. In silico ADMET properties of ISABH and Ni-ISABH

\begin{tabular}{|c|c|c|c|c|c|c|c|}
\hline Compounds & HIA & HOB & BBB & PPB & $\begin{array}{l}\text { CYP Inhibitory/ } \\
\text { substrate }\end{array}$ & Carcinogen-icity & $\begin{array}{l}\text { Acute oral toxicity } \\
(\mathrm{kg} / \mathrm{mol})\end{array}$ \\
\hline ISABH & + & + & + & 0.677 & none & none & 2.057 \\
\hline $\mathrm{Ni}-\mathrm{ISABH}$ & + & + & + & 0.807 & none & none & 2.810 \\
\hline
\end{tabular}

HIA: human intense absorption, HOB: human oral bioavailability, BBB: blood brain barrier, PPB: plasma protein binding 
with optimum coordination number (OCN). This coordination type have negligible contributions to the binding affinities due to the large shielding effect of the metal complexes with OCNs. In contast, $\mathrm{Ni}$ (II) with coordination number $(\mathrm{CN})$ less than OCN produced ML type in tetrahedral mode and reffered as hypo-coordinated metal ion, shows large contribution to binding affinities because of the small shielding effect. Figure 1 also shown that the distances of metalcoordinating atom in metal complexes increase with the increasing of CNs. This fact supports that the M-L strength in ML $n$ becomes weaker as $n$ increases [26].

Interactions and binding modes of the best poses of ISABH, Co-ISABH, Cu-ISABH, Ni-ISABH, and ZnISABH with the CDK- 6 protein were then visualized. Figure 3 indicates that Ni-ISABH interacted with Glu 99 and Asp 104 residues through hydrogen bonding, while Co-ISABH, Cu-ISABH, and Zn-ISABH connected with Asp 104 residue on CDK-6 protein. ISABH interacted with Val 101 residue as 3NU co-crystals on the 3NUP3NU crystal structure (Figure 4).

Lipinski's rule of five states that a compound with excellent drug-like properties has a molecular weight $(\mathrm{MW}) \leq 500$ Dalton, $\log \mathrm{P} \leq 5$, number of hydrogen bond donors $(\mathrm{HBD}) \leq 5$, and number of hydrogen bond acceptors $(\mathrm{HBA}) \leq 10$ [27]. The $\log \mathrm{P}$ value which is the logarithm of the partition coefficient between $n$-octanol and water $\left(\log \left(c_{\text {octanol }} / c_{\text {water }}\right)\right)$ can be used to estimate the hydrophilicity of a compound. The high hydrophilicity correlates with $\operatorname{low} \log P$ values and favorable absorption and permeation. Druglikeness analysis (Table 1) showed that ISABH and the complexes of cobalt (II), nickel (II), copper (II), and zinc (II) have acceptable hydrophilicity indicated by low $\log P$ values (1.44-2.48). Cu-ISABH, Co-ISABH, and $\mathrm{Zn}-\mathrm{ISABH}$ did not meet the requirement of hydrogen bond acceptors, hydrogen bond donors, and molecular weight parameters. Those three complexes have $\mathrm{MW} \geq 600$ Dalton, $\mathrm{nHBA} \geq 10$, and $\mathrm{nHBA} \geq 5$. In contrast, ISABH and Ni-ISABH met all the criteria, namely $\mathrm{BM} \leq 500, \mathrm{nHBA} \leq 5$, and $\mathrm{nHBD} \leq 5$. Based on these data, ISABH and Ni-ISABH have valuable drug-like properties.

The evaluation of absorption, distribution, metabolism, excretion, and toxicity was then performed to predict the pharmacological properties of ISABH and Ni-ISABH. The results (Table 2) indicated that both ISABH and Ni-ISABH have positive values for HIA and $\mathrm{HOB}$ indicating a decent absorption in human body and tolerable absorption rates in human intestine. ISABH and Ni-ISABH also showed promising distribution expressed by positive blood brain barrier parameter and plasma protein binding (PPB) of $67.7 \%$ and $80.7 \%$. An absolute distribution requires positive blood brain barrier and plasma protein binding distribution capabilities. The blood brain barrier parameter represents the central nervous system vascularization of blood vessels which strictly regulates the movement of ions, molecules, and cells between the blood and brain [28]. Furthermore, the large percentage of plasma protein binding illustrates the better distribution of compounds in the blood because of plasma protein binding value represents the degree of protein distribution in the blood [29]. The distribution prediction based on inhibition and substrate P-glycoprotein parameters is important because P-glycoprotein is one of the drug carriers that determines the absorption and excretion of various drugs. Table 2 informs that ISABH and NiISABH were non-substrate and non-inhibitor to P-glycoprotein. Moreover, ISABH and Ni-ISABH were non-carcinogenic with fairly safe acute oral toxicity values of 2.057 and $2.810 \mathrm{~kg} / \mathrm{mol}$, respectively, which fall into the category III of acute oral toxicity.

To summarize, the docking study of ISABH, CoISABH, Cu-ISABH, Ni-ISABH, and Zn-ISABH have successfully been performed by redocking the $3 \mathrm{NU}$ co-crystal ligand on the active site of the CDK-6 protein followed by cross-docking. Ni-ISABH showed the best binding affinity value of $-9.4 \mathrm{kcal} / \mathrm{mol}$ and interacted with Glu 99 and Asp 104 residues through hydrogen bonding. Ni-ISABH met the Lipinski rule of five and had acceptable drug-like and pharmacological properties.

\section{Conclusion}

The molecular docking study of ISABH, CoISABH, Cu-ISABH, Ni-ISABH, Zn-ISABH was carried out against the CDK- 6 protein and resulted in a binding affinity value of $-9.4 \mathrm{kcal} / \mathrm{mol}$ for $\mathrm{Ni}-\mathrm{ISABH}$ lower than ISABH $(-8.5 \mathrm{kcal} / \mathrm{mol})$. Visualization of the docking results informed that Ni-ISABH interacted with CDvaK-6 with glutamic acid 99 and aspartic acid 104 residues via hydrogen bonding. The drug-likeness properties analysis showed that Ni-ISABH complied Lipinski rules of five with BM $\leq 500, \log P 1.44, \mathrm{nHBA} \leq 5$, and $\mathrm{nHBD} \leq 5$. NiISABH displayed a valuable absorption, distribution, 
metabolism, excretion and was non-carcinogenic with safe acute oral toxicity.

\section{Acknowledgment}

None.

\section{Declaration of interest}

The authors declare no conflict of interests in the journal publication of this article.

\section{Author contribution}

AF constructed the study design. YRN performed and analyzed the molecular docking and pharmacological properties studies. AF prepared the manuscript and revised the final version of the paper. YRN and AF have read the final manuscript and approved the submission.

Received: 8 January 2021

Accepted: 14 February 2021

Published online: 10 August 2021

\section{References}

1. Lee DJ, Zeidner JF. Cyclin-dependent kinase (CDK) 9 and 4/6 inhibitors in acute myeloid leukemia (AML): a promising therapeutic approach. Expert Opin Investig Drugs. 2019;28: 989-1001. doi:10.1080/13543784.2019.16 78583

2. Pavlova NN, Thompson CB. The emerging hallmarks of cancer metabolism. Cell Metab. 2016;23: 27-47. doi:10.1016/j.cmet.2015.12.006

3. Mohammad T, Batra S, Dahiya R, Baig MH, Rather IA, Dong J-J, et al. Identification of High-Affinity Inhibitors of Cyclin-Dependent Kinase 2 Towards Anticancer Therapy. Molecules. 2019;24. doi:10.3390/molecules24244589

4. Lim S, Kaldis P. Cdks, cyclins and CKIs: roles beyond cell cycle regulation. Development. 2013;140: 3079-3093. doi:10.1242/dev.091744

5. Zhang $\mathrm{M}$, Zhang L, Hei R, Li X, Cai H, Wu X, et al. CDK inhibitors in cancer therapy, an overview of recent development. Am J Cancer Res. 2021;11: 1913-1935.

6. Narasimha AM, Kaulich M, Shapiro GS, Choi YJ, Sicinski P, Dowdy SF. Cyclin D activates the Rb tumor suppressor by mono-phosphorylation. Elife. 2014;3. doi:10.7554/ eLife.02872

7. Chen L, Wang X, Cheng H, Zhang W, Liu Y, Zeng W, et al. Cyclin Y binds and activates CDK4 to promote the G1/S phase transition in hepatocellular carcinoma cells via $\mathrm{Rb}$ signaling. Biochem Biophys Res Commun. 2020; doi:10.1016/j.bbrc.2020.09.127

8. Chen F, Liu C, Zhang J, Xu W, Zhang Y. Progress of CDK4/6 inhibitor palbociclib in the treatment of cancer.
Anticancer Agents Med Chem. 2018;18: 1241-1251. doi: 10.2174/1871521409666170412123500

9. Varun, Sonam, Kakkar R. Isatin and its derivatives: a survey of recent syntheses, reactions, and applications. Medchemcomm. 2019;10: 351-368. doi:10.1039/c8md00585k

10. Brandão P, Marques C, Burke AJ, Pineiro M. The application of isatin-based multicomponent-reactions in the quest for new bioactive and druglike molecules. Eur J Med Chem. 2021;211: 113102. doi:10.1016/j.ejmech.2020.113102

11. Al-Warhi T, El Kerdawy AM, Aljaeed N, Ismael OE, Ayyad RR, Eldehna WM, et al. Synthesis, Biological Evaluation and In Silico Studies of Certain OxindoleIndole Conjugates as Anticancer CDK Inhibitors. Molecules. 2020;25. doi:10.3390/molecules25092031

12. Al-Salem HS, Arifuzzaman M, Alkahtani HM, Abdalla AN, Issa IS, Alqathama A, et al. A Series of Isatin-Hydrazones with Cytotoxic Activity and CDK2 Kinase Inhibitory Activity: A Potential Type II ATP Competitive Inhibitor. Molecules. 2020;25. doi:10.3390/ molecules 25194400

13. Ali AQ, Teoh SG, Eltayeb NE, Ahamed MBK, Majid AA. Synthesis of nickel(II) complexes of isatin thiosemicarbazone derivatives: in vitro anti-cancer, DNA binding, and cleavage activities. J Coord Chem. 2014;67: 3380-3400. doi:10.1080/ 00958972.2014.959943

14. Ferraz de Paiva RE, Vieira EG, Rodrigues da Silva D, Wegermann CA, Costa Ferreira AM. Anticancer Compounds Based on Isatin-Derivatives: Strategies to Ameliorate Selectivity and Efficiency. Front Mol Biosci. 2020;7: 627272. doi:10.3389/fmolb.2020.627272

15. Cho YS, Borland M, Brain C, Chen CH-T, Cheng H, Chopra R, et al. 4-(Pyrazol-4-yl)-pyrimidines as selective inhibitors of cyclin-dependent kinase 4/6. J Med Chem. 2010;53: 7938-7957. doi:10.1021/jm100571n

16. Hunoor RS, Patil BR, Badiger DS, V. M. C, Muchchandi IS, Gudasi KB. $\mathrm{Co}(\mathrm{II}), \mathrm{Ni}(\mathrm{II}), \mathrm{Cu}(\mathrm{II})$ and $\mathrm{Zn}(\mathrm{II})$ complexes of isatinyl-2-aminobenzoylhydrazone: synthesis, characterization and anticancer activity. Appl Organomet Chem. 2015;29: 101-108. doi:10.1002/aoc.3252

17. Trott O, Olson AJ. AutoDock Vina: improving the speed and accuracy of docking with a new scoring function, efficient optimization, and multithreading. J Comput Chem. 2010;31: 455-461. doi:10.1002/jcc.21334

18. Dallakyan S, Olson AJ. Small-molecule library screening by docking with PyRx. Methods Mol Biol. 2015;1263: 243-250. doi:10.1007/978-1-4939-2269-7_19

19. Allen WJ, Rizzo RC. Implementation of the Hungarian algorithm to account for ligand symmetry and similarity in structure-based design. J Chem Inf Model. 2014;54: 518-529. doi:10.1021/ci400534h

20. Daina A, Michielin O, Zoete V. SwissADME: a free web tool to evaluate pharmacokinetics, drug-likeness and medicinal chemistry friendliness of small molecules. Sci Rep. 2017;7: 42717. doi:10.1038/srep42717

21. Yang H, Lou C, Sun L, Li J, Cai Y, Wang Z, et al. admetSAR 
2.0: web-service for prediction and optimization of chemical ADMET properties. Bioinformatics. 2019;35: 1067-1069. doi:10.1093/bioinformatics/bty707

22. Ramírez D, Caballero J. Is It Reliable to Take the Molecular Docking Top Scoring Position as the Best Solution without Considering Available Structural Data? Molecules. 2018;23. doi:10.3390/molecules23051038

23. Bell EW, Zhang Y. DockRMSD: an open-source tool for atom mapping and RMSD calculation of symmetric molecules through graph isomorphism. J Cheminform. 2019;11: 40. doi:10.1186/s13321-019-0362-7

24. Selvaganapathy M, Raman N. Pharmacological activity of a few transition metal complexes: A short review. J Chem Biol Ther. 2016;01. doi:10.4172/2572-0406.1000108

25. Gorgulu G, Cicek MB, Dede B. Novel aminoketooxime ligand and its $\mathrm{cu}(\mathrm{ii})$ and $\mathrm{mn}(\mathrm{ii})$ complexes: synthesis, characterization and molecular docking studies. Acta Phys Pol A. 2018;133: 250-255. doi:10.12693/APhysPolA.133.250
26. Chen D, Li Y, Guo W, Li Y, Savidge T, Li X, et al. The shielding effect of metal complexes on the binding affinities of ligands to metalloproteins. Phys Chem Chem Phys. 2019;21: 205-216. doi:10.1039/c8cp06555a

27. Lipinski CA. Drug-like properties and the causes of poor solubility and poor permeability. J Pharmacol Toxicol Methods. 2000;44: 235-249. doi:10.1016/S10568719(00)00107-6

28. Daneman R, Prat A. The blood-brain barrier. Cold Spring Harb Perspect Biol. 2015;7: a020412. doi:10.1101/ cshperspect.a020412

29. Bohnert T, Gan L-S. Plasma protein binding: from discovery to development. J Pharm Sci. 2013;102: 29532994. doi:10.1002/jps.23614 